\title{
Re-using urban industrial areas: the case of 's-Hertogenbosch, the Netherlands
}

\author{
W. van der Toorn Vrijthoff \\ Delft University of Technology, Faculty of Architecture, \\ Department of Real Estate and Project Management, \\ Delft, The Netherlands
}

\begin{abstract}
In the 20th century, and especially after World War II, European cities began to grow very rapidly. Historic inner-city areas currently occupy less than $5 \%$ of the total urban area of the old cities. This implies that the industrial sites dating from the beginning of the 20th century are no longer situated on urban peripheries, but are to be found in the central areas of cities. A consequence of this growth was that the old city centers became far too small to meet the needs of these enlarged cities, so there was also a growing need to expand the centers.

To meet this need, many of the old urban industrial sites in European cities have been transformed into functional extensions of the old inner cities. In some cases, the old buildings and infrastructure have been included in the new plans to retain the historic character of the area; in other cases re-development has brought about a total transformation, making it hard to recognize anything of the historic appearance in the new one.

This paper focuses on 's-Hertogenbosch, an old city in the southern part of the Netherlands that gained its charter just before 1200. Close to the city centre there was an old industrial area being transformed into "a monument for the future". It will become a new part of the city centre, providing 1,400 houses and $180,000 \mathrm{~m}^{2}$ of office space. In addition, $30,000 \mathrm{~m}^{2}$ of space will be reserved for hotel and catering businesses, retail outlets and culture. This paper tells the story of how this industrial area is being transformed; the vision behind it, the plans, and how they will be carried out. Special attention will be given to how these plans relate to, or ignore, features of the historic site.

Keywords: urban transformation, city centre, industrial areas, public-private partnership.
\end{abstract}




\section{Urban growth and transformation}

In Europe, and also in the Netherlands, in the period following World War II, building work was primarily directed towards repairing war damage. The next priority, after that, was to create living space for the steadily growing population. The steadily decreasing average number of people per household, combined with a favourable economic climate, resulted in a constantly growing demand for quantitative space. In response to this demand, building production was mainly oriented towards extending the urban area. In fact, $75 \%$ of current urban real estate was built in the last 60 years by transforming rural into urban areas.

\subsection{Increase in scale and concentration}

The spatial functional concepts on which urban-area extension was based in the decades following World War II were greatly influenced, from 1929 onwards, by ideas submitted by the Congress International d'Architecture Moderne (CIAM) [International Congress on Modern Architecture] (Ministry of Housing, Spatial Planning and the Environment, 2004). At least, that is the generally accepted explanation for the realization of large post-war housing areas where the spatial functions are separated. This monofunctionality, in combination with uniformity, is now recognized as one of the main reasons why these areas are so unattractive. The question is whether it could have been done differently. A variant of this question arises in connection with the restructuring assignments for those areas. Is it possible to counterbalance the monofunctionality and uniformity by restructuring these areas to transform them into multifunctional areas with a strongly differentiated form? That would be difficult, if not impossible. The monofunctionality is not a characteristic that, in hindsight, we can ascribe entirely to the CIAM. On the one hand, monofunctionality is largely a consequence of a very strong growth in the use of living space and, on the other, on developments aimed at concentration and scale increase in other sectors. These trends manifested themselves strongly, especially during the second half of the 20th century, and are still present. They have led to the segregation of urban functions, which implies that the traditional mix of functions has become restricted to a limited number of urban areas. Good examples of this are the historic inner city and the urban centre, both of which have long been viewed as areas characterized by a broad mix of functions. These are areas where the functional profile has changed drastically in recent decades, because it was accompanied by the need for expansion.

\subsection{The changing profile of the city center}

The post-World War II period was a time of renewal throughout Europe. For a decade, it was supported by sustained economic growth. This was coupled by a steady growth in car ownership. The historic inner city was an area in which all urban facilities were concentrated, but accessibility to that area was becoming more and more of a problem. The first reaction to the exodus of commercial activity was to concentrate on modifying the spatial structures, thereby adapting 
the historic centers to the requirements of the time. The changes were particularly rigorous in the United States. Reacting to that development, Jane Jacobs [1] noted that the unique qualities of old city centers were rapidly being effaced. Though rather more slowly, and not quite as comprehensively, the same thing could be seen happening in Europe.

It soon became clear that the suburbanization of economic life could not be stopped by metamorphosing urban spatial structures. A division of economic interests took place, which caused the historic centre to change from being a place of production to one of consumption. A repetition of this process is imminent today.

For years, the geographical centre of gravity of consumer expenditures had been located in the city centre. Because growth in consumer expenditure is coupled with a substantial increase in spatial requirements, this is now changing. A self-evident, but ill-advised, reaction to this trend is to instigate a far-reaching re-organization of the city centre so as to create more space. By so doing, there is a high probability that the unique spatial quality of the old centre will be destroyed, and that it will become a poor alternative to locations that are both more spacious and more accessible. Instead of taking drastic measures to transform old centers, extending them is a better alternative. Such extensions must then meet the spatial requirements of businesses and individuals who prefer to be located in urban centers. In many cities, such locations are present in the form of industrial sites that date from just before or just after World War II. These areas were built on the edges of cities, often near a railway, but nowadays, because of urban expansion these same areas lie in the heart of urban centers.

\subsection{Area market misfit and transformation}

Transforming an existing urban area interferes with the societal functioning of that area. This implies that there are interests at stake that extend beyond those of the local parties who are directly involved. It also implies that, in many cases, it is local politics that set the conditions for the decision-making process on a local level. Shortly after the war, the political aims behind the extension of urban areas were not only unambiguous but also similar. Opinions nowadays are often divided and the aims are incompatible. Attempts to reach a consensus about a spatial/functional intervention on a local level are often very time consuming. There is always the danger that, with changes in the balance of power within local politics, directional changes will take place that will seriously frustrate the process of furthering restructuring. A large number of parties can be identified at local level, ranging from owners to users and from public to private parties, all of which have different interests, aims and means. The extent to which all these parties benefit from local transformation differs widely. This provokes discussion, frequent lengthy negotiating procedures and active resistance from some of the parties involved.

Neither the current functioning of an area, nor the immediate environment should be inconvenienced during a process of spatial intervention. It is a matter of 'repairing a running engine' and that is an extremely difficult task. There is often a series of smaller, connected problems, between which interaction occurs. 
These smaller problems cannot be solved either separately or one after the other, because the solution to one partial problem affects a series of other partial problems. All these smaller problems therefore have to be approached as a totality of linked parts, because integrated partial problems require integral solutions.

Comprehensive area development is seen as the answer to comprehensive area-market misfit

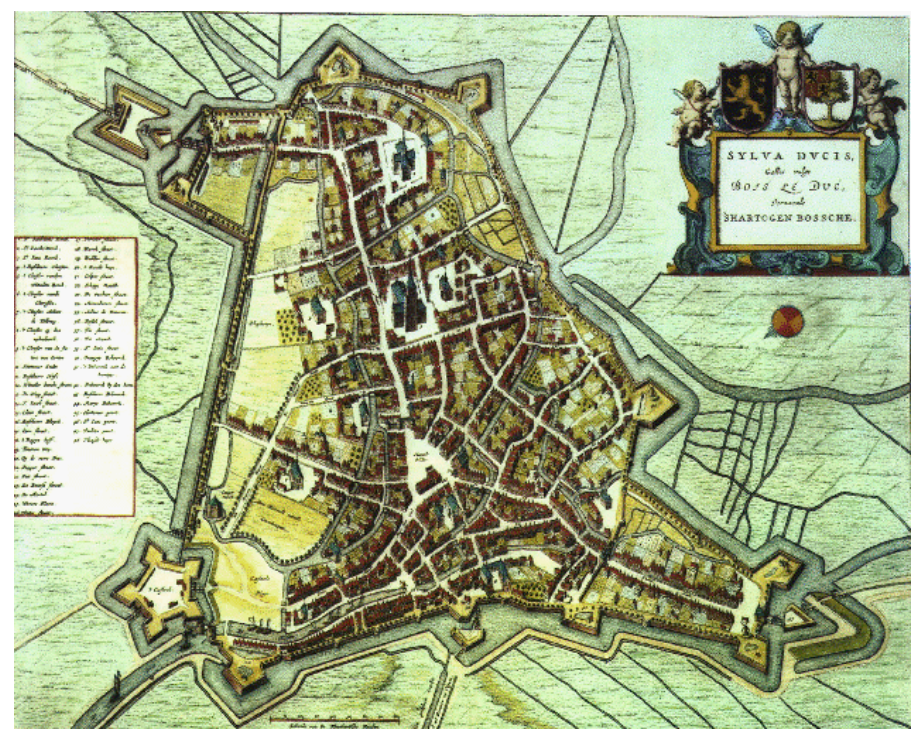

Figure 1: A historical map of the city of 's-Hertogenbosch. Source: Blaeu's Toonneel der Steden from 1652.

\section{The Case of 's-Hertogenbosch}

\subsection{The historical background}

's-Hertogenbosch is an average-sized Dutch city, dating from the 13 th century. It currently has a population of 132,000 . The medieval structure of the historical part of the city, with its ramparts and pattern of narrow streets, has been largely preserved. The Binnendieze, a historic watercourse that runs partly underground through the city, is also still there, thus confirming the authenticity of that part of the historic centre. The old city is situated on a sandbar, surrounded by marshy land. Because of this, urban expansion was very problematic in the past. In addition, 's-Hertogenbosch was a fortified city with impressive, sturdy ramparts. The city plan of 1652, showed in figure 1, is still very recognizable in the present city plan. In the 19th century, the city was forced to seek solutions for the growing need for space by opting for a high concentration of buildings within the city walls. It was only in 1874, when a law was passed stating that the 
fortifications of Dutch towns and cities were no longer functional, that creative solutions were sought for making the surrounding marshy land suitable for building. The railway and the station were built on the periphery of the historic inner city, an area in which 590 national and municipal monuments are situated. These buildings strongly determine its authenticity, historical character, and therefore the attractiveness of this area. For this reason, the area has a protected status, so that it is difficult to realize any spatial and functional interventions. "Any urban planning, in almost any European city, cannot now occur other than within the constraining context of the conserved urban landscape" [2]. The inner city also plays an important role in the economic functioning of the city, because more than a third of the employment is situated here. 's-Hertogenbosch has maintained and strengthened its past role as an urban centre, however, not without the growing need to extend it.

\subsection{The need to extend the city centre}

Because of the economic growth of 's-Hertogenbosch, an ever greater pressure was put on the inner city to accommodate offices, shops and housing. Ever since the 1980s, the municipality had been searching for possibilities to extend the inner city.

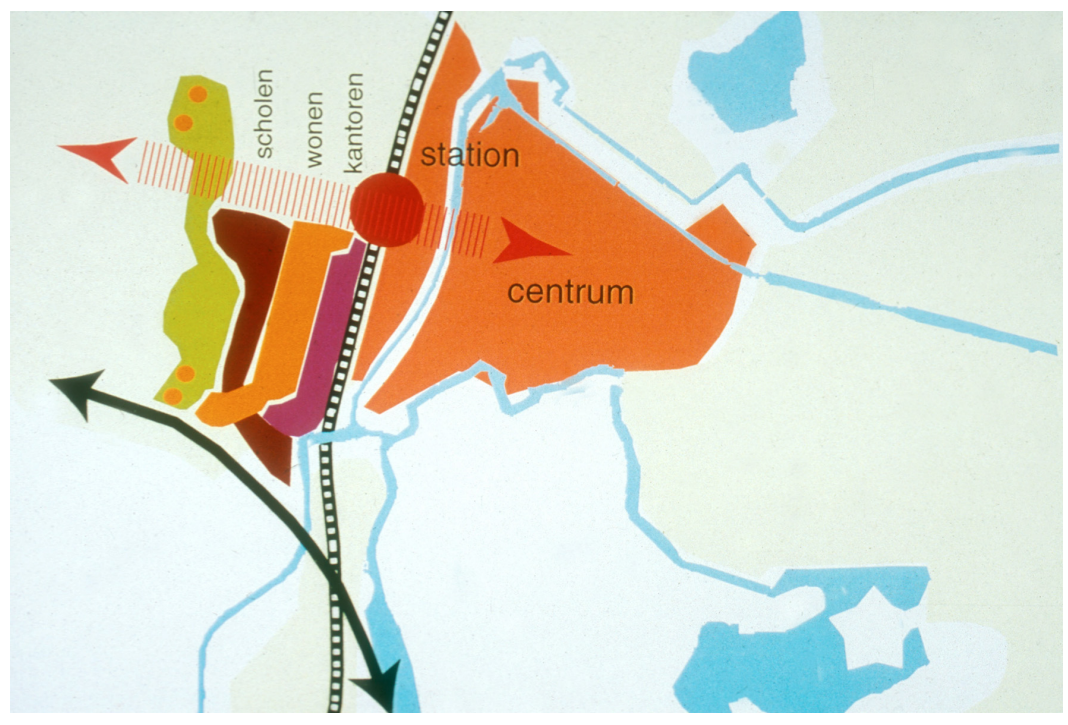

Figure 2: $\quad$ Scheme of the city and the extension to the west.

At the end of the 1980s, the decision was taken to extend the inner city in a westerly direction. The challenging title given to this risky undertaking was the 'leap over the railway'. On the western side of the railway was an industrial site that had been developed around the war years. Many of the businesses that had originally occupied this site had moved, in the meantime, to locations that 
offered more space, were more accessible and where carrying out the business was less of a nuisance for those in the immediate surroundings. Existing buildings started to become empty in the 1980s. This offered perspectives for large-scale redevelopment. Figure 2 is giving a schematic view of the extension.

The main specification for redeveloping the area around the railway was to 'lift' the inner city over the railway to create a place in the western section of that zone for city-centre functions that could not be accommodated in the historic inner-city due to lack of space. Such was the location, that it offered possibilities to create a new, high-quality urban environment, with new, high-density architecture, and modern solutions. An additional specification was to create space for the new 'spatial claimants' on the market - large-scale organizations in education, the service industries and banking - that had resulted from mergers, the functions of which, as far as scale level was concerned, not longer fitted into the finely meshed parceling out of the historic inner-city.

\subsection{Functional program and flexibility}

A number of characterizations of the area were included in the points of departure, in the first part of the Masterplan. These are characterizations that are directional for the market position aimed at within the urban context. Of particular importance in this respect is the functional relation with the historic inner-city.

- “'s-Hertogenbosch, is searching for space, and especially in its busy inner city that attracts more and more activities, to control, but at the same time to stimulate, this growth process" and

- "Because the development of the railway zone involves an extension of the inner city by functionally redeploying and by eliminating the barrier effect of the railway, the opportunity arises for carefully developing the characteristic inner-city by utilizing culturalhistorical values" (Masterplan, 1996) [3].

The Masterplan largely determines the spatial quality of the area. The functionality of the programme that has to be realized was established as follows:

It is anticipated that the relations between functions will be as follows:

- Housing

- Offices

- Office-related buildings/showrooms

- Culture and Education

- Commercial functions

$$
\begin{aligned}
& 30-50 \% \\
& 20-40 \% \\
& 10-25 \% \\
& 0-10 \% \\
& 2-5 \%
\end{aligned}
$$

These are margins that are large enough to accommodate the radically different functional programmes of variants in the plans. Market developments during the formation of plans have been determining for optimizing the functions within the margins indicated. That has resulted in a reduction in the office share compared with the initial plans and an enlargement in the share of the housing function. 
Flexibility has thus made it possible to move with the market, contributing towards a financially positive end-result.

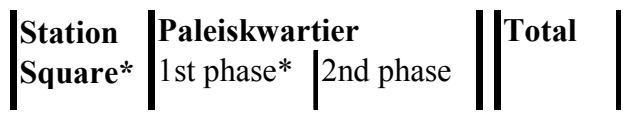

\begin{tabular}{l}
\hline Surface (hectares) \\
\hline$\overline{\text { Offices }\left(\mathrm{m}^{2}\right)}$ \\
\hline$\overline{\text { Other commercial functions }\left(\mathrm{m}^{2}\right)}$ \\
\hline$\overline{\text { Dwellings (Number of) }}$ \\
\hline
\end{tabular}

\begin{tabular}{|c|c|c|c|}
\hline 81 & 10 & 18 & 36 \\
\hline 10.300 & 91.000 & 110.600 & 211.900 \\
\hline 6.800 & 6.300 & 32.700 & 45.800 \\
\hline 16 & 307 & 1.200 & 1.523 \\
\hline
\end{tabular}

Figure 3: The functional programme.

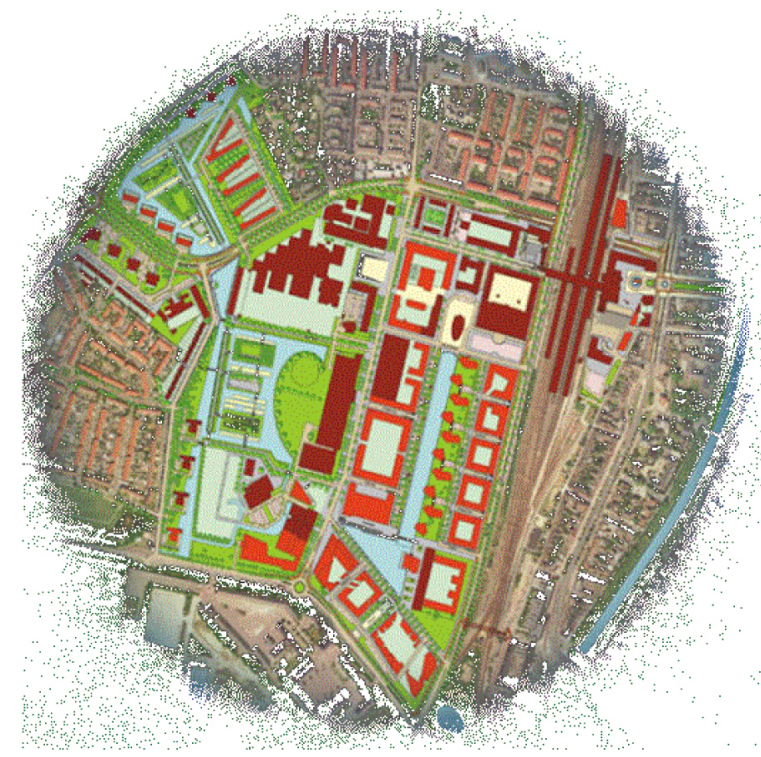

Figure 4: The redevelopment area.

During the plan formation, ambitions with respect to concentration and urban quality were adjusted to ever higher levels. That has brought an area into existence that many people view as the modern equivalent of the historic innercity of 's-Hertogenbosch. Figure 3 shows the realized functional programme and in figure 4 the redevelopment plan is shown.

\subsection{Public private partnership}

The choice made for the Palace District (Paleiskwartier) was a far-reaching public-private partnership. The municipality was active in developing the plan, 
together with three commercial parties. The utilization of both land and buildings was coordinated under the Paleiskwartier BV, the limited company set up to carry out the Palace District project, in which each of the four parties had an equal, $25 \%$, share of the ownership.

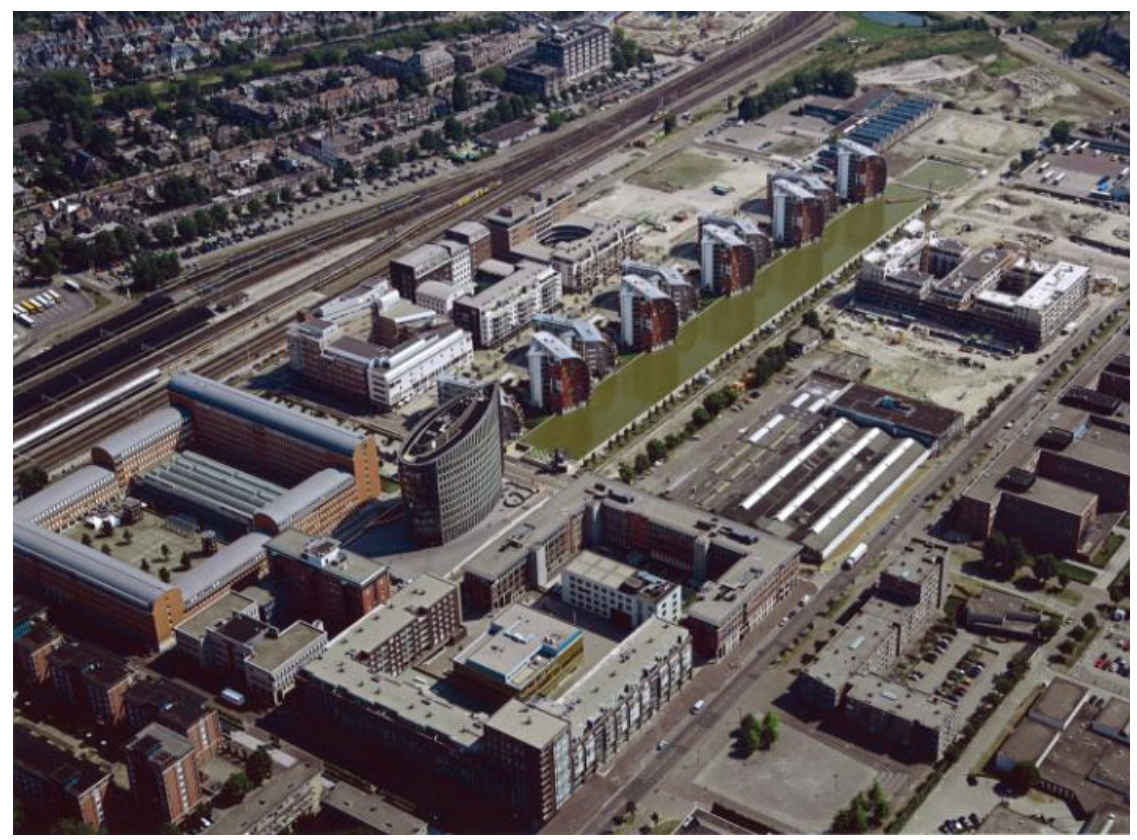

Figure 5: The area in transformation, central the water basin with the underground parking facility.

The early acquisition of land stimulated the process and gave an advantage over other parties. This prevented encroachment on ownership, and also speculative purchasing by other private parties which could have forced up the prices. Had no action been taken, then other (unwanted) parties would have been able to acquire claims on land in the area. Early acquisition was thus essential. The fragmented ownership of land was breached, which gave rise to an important condition for integral area development and also to the conditions within which urban design aspirations and ambitions for the planning area could be achieved. The redevelopment of the area was set up in phases because, at the time when the plan started to be carried out, part of the area was still in use. This is why the decision was made to base the new urban architectural structure on the one that already existed. Although the area as a whole was totally redeveloped, it was nevertheless decided to build an underground parking garage, under the elongated water basin, in the central part of the planning area. Figure 5 is showing the area in transformation with the water basin in the center of the area. This provided an underground solution for parking pressure in the area, and had a positive effect on the quality of public space. 
Concealed under the water feature, there is now a public parking garage, with enough space for 1070 vehicles. In this way, public space in this intensively built-up area has been qualitatively designed, so that only a limited number of parking places (approximately 200) are situated on ground level [3].

\section{Obsolete industrial sites in the Netherlands}

It has been estimated that on 1 January 2003 there was a gross area of 93,800 hectares of industrial land in the Netherlands, divided between 3600 business sites (IBIS, Integral Bouw Informatie Systeem) [4]. Of this, 24,400 hectares were open ground used as, or earmarked for, public use, infrastructure, green facilities, etc. The net remaining area of 69,500 hectares is built-up land. The same research also revealed that, of the 93,800 hectares of industrial land, $30 \%$ is obsolete and eligible for redevelopment. This is approximately 30,000 hectares, which represents a building location 800 times as large as the location in 's-Hertogenbosch, described earlier in this paper. This location is large enough to accommodate the expanding needs of urban functions, including housing, for very many years to come.

\section{References}

[1] Jacobs, J., 1961, The death and life of great American cities, New York

[2] Ashworth, G.J., 2002, Modern Europe, Arnold Publishers, London

[3] Bruil, I. et al., 2004, Integrale gebiedsontwikkeling [Integral area development], Amsterdam, SUN publishers.

[4] IBIS, 2003, Werklocaties 2003:Hoofdrapportage, Den Haag 